\title{
Bone marrow suppression and severe anaemia associated with persistent Plasmodium falciparum infection in African children with microscopically undetectable parasitaemia
}

\author{
Marie Helleberg1, Bamenla Q Goka², Bartholomew D Akanmori³, \\ George Obeng-Adjei ${ }^{2}$, Onike Rodriques ${ }^{2}$ and Jorgen AL Kurtzhals*1
} \begin{abstract}
Medical Research, Legon, Ghana
Email: Marie Helleberg - mariehelleberg@hotmail.com; Bamenla Q Goka - bamenla@yahoo.co.uk; Bartholomew D Akanmori - bakanmori@noguchi.mimcom.net; George Obeng-Adjei - goadjei@yahoo.com;

Onike Rodriques - onifred@ghana.com; Jorgen AL Kurtzhals* - j.kurtzhals@dadlnet.dk

* Corresponding author
\end{abstract}

Address: ${ }^{1}$ Centre for Medical Parasitology, Department of Clinical Microbiology 7602, Copenhagen University Hospital, 2100 Copenhagen, Denmark, ${ }^{2}$ Department of Child Health, Korle-Bu Teaching Hospital, Accra, Ghana and ${ }^{3}$ Immunology Unit, Noguchi Memorial Institute for

Published: 0 I December 2005

Malaria Journal 2005, 4:56 doi:10.1186/1475-2875-4-56

This article is available from: http://www.malariajournal.com/content/4/1/56

(C) 2005 Helleberg et al; licensee BioMed Central Ltd.

This is an Open Access article distributed under the terms of the Creative Commons Attribution License (http://creativecommons.org/licenses/by/2.0), which permits unrestricted use, distribution, and reproduction in any medium, provided the original work is properly cited.
Received: 21 July 2005

Accepted: 01 December 2005

\begin{abstract}
Background: Severe anaemia can develop in the aftermath of Plasmodium falciparum malaria because of protracted bone marrow suppression, possibly due to residual subpatent parasites.

Materials and methods: Blood was collected from patients with recent malaria and negative malaria microscopy. Detection of the Plasmodium antigens, lactate dehydrogenase (Optimal ${ }^{\circledR}$ ), aldolase and histidine rich protein 2 (Now malaria ${ }^{\circledR}$ ) were used to differentiate between patients with (I) no malaria, (2) recent cleared malaria, (3) persistent $P$. falciparum infection. Red cell distribution width (RDW), plasma levels of soluble transferrin receptor (sTfR) and erythropoietin (EPO) were measured as markers of erythropoiesis. Interleukin (IL) 10 and tumour necrosis factor (TNF) $\alpha$ were used as inflammation markers.

Results: EPO was correlated with haemoglobin, irrespective of malaria $(R=-0.36, P<0.00 I)$. Persistent $P$. falciparum infection, but not recent malaria without residual parasites, was associated with bone marrow suppression i.e., low $\operatorname{RDW}(P<0.001$ vs. $P=0.56)$ and $\operatorname{sTfR}(P=0.02$ vs. $P=$ 0.36). TNF- $\alpha$ and IL-I 0 levels were not associated with bone marrow suppression.

Conclusion: In the treatment of malaria, complete eradication of parasites may prevent subsequent development of anaemia. Severely anaemic children may benefit from antimalarial treatment if antigen tests are positive, even when no parasites can be demonstrated by microscopy.
\end{abstract}

\section{Introduction}

Anaemia is a common, life-threatening complication of Plasmodium falciparum malaria in African infants and young children. The anaemia develops when accelerated removal of erythrocytes is not compensated by the bone marrow. Bone marrow suppression is generally present in all malaria patients [1] and has also been described in asymptomatic $P$. falciparum infection [2]. The fact that some malaria patients develop severe anaemia, whereas others retain normal or near normal haemoglobin (Hb) 
must thus be explained by the amount of erythrocyte destruction during the period until return of normal bone marrow function. The anaemia may either develop rapidly with severe, acute haemolysis, or take a slow smouldering course, with a relatively slow rate of erythrocyte destruction in the presence of persistent bone marrow suppression [3]. Data on the duration of bone marrow suppression after a malaria attack are conflicting. In some studies there has been evidence of hypoproliferative erythropoiesis and dyserythropoiesis for weeks following treatment $[4,5]$, while other studies have shown that bone marrow suppression is reversed rapidly after treatment $[1,6]$.

In areas where malaria is endemic, a high number of children with severe anaemia but without detectable parasites are hospitalized each year coinciding with the peak of malaria transmission. The history of recent febrile illness and the presence of detectable circulating antigens strongly suggest that these children suffer from the late effects of a recent malaria attack [7]. The question is whether there are signs of bone marrow suppression in these patients, and if so, whether this bone marrow suppression is due to a sustained effect of the malaria attack or to the persistence of parasites that are undetectable by routine microscopy. In the latter case, it is possible that these patients would benefit from a repeated course of antimalarial treatment.

Patients with severe malarial anaemia have an increased ratio between the pro-inflammatory cytokine, tumour necrosis factor (TNF)- $\alpha$, and the anti-inflammatory cytokine, interleukin (IL)-10 [8], and it has been proposed that inflammatory cytokines may be a causative factor for malarial anaemia $[9,10]$. If so, protracted bone marrow suppression in the aftermath of a malaria attack might be due to persistence of a dysregulated inflammatory response. However, mild and moderate malarial anaemia is not associated with an inverse ratio between TNF- $\alpha$ and IL-10 [2].

The purpose of the present study was to test the hypothesis that an impaired erythropoietic response to anaemia is associated with a persistent malarial infection in patients without microscopically detectable parasites. In order to differentiate between recent and persistent $P$. falciparum infection, two rapid tests for soluble malarial antigens, Now $^{\boxplus}$ ICT Malaria P.f/P.v (Binax, US) and Optimal ${ }^{\boxplus}$ (DiaMed AG, Schweiz) were performed. Binax is based on detection of histidine rich protein 2 (HRP2) and aldolase and can remain positive for weeks following treatment of the infection [11]. Optimal ${ }^{\varpi}$, on the other hand, detects parasite derived lactate dehydrogenase ( $\mathrm{pLDH}$ ) and test results are positive only in the presence of live parasites [12].
Red cell distribution width (RDW) and plasma levels of erythropoietin (EPO) and soluble transferrin receptor (sTfR) were measured as markers of erythropoiesis. RDW is a measure of size variation in red blood cells and is increased when erythropoiesis is stimulated [13]. sTfR is secreted mainly by erythroblasts, and plasma levels are increased when turnover in the bone marrow is raised as in haemolytic anaemia, whereas levels are normal in the anaemia of chronic disease [14]. Plasma levels of TNF- $\alpha$ and IL-10 were analysed to determine if the bone marrow suppression was correlated to dysregulated inflammation.

\section{Materials and methods}

The study took place at the Department of Child Health, Korle Bu Teaching Hospital, Accra, Ghana during the malaria season, July and August, 2003. Two groups of children aged $0.5-12$ years were consecutively recruited. Both groups consisted of children with a presumptive or confirmed diagnosis of recent malaria but without detectable parasites in Giemsa-stained blood films, examined by ordinary microscopy.

\section{Group I}

Patients admitted to the emergency room with a presumptive diagnosis of acute malaria but with a negative microscopic test for malaria. The majority of these patients had received treatment for malaria either at home or in various health facilities prior to being referred to hospital. Those who had haemoglobin $(\mathrm{Hb}) \leq 5 \mathrm{~g} / \mathrm{dl}$ or $\mathrm{Hb} \geq 8 \mathrm{~g} / \mathrm{dl}$ were included, unless they had a history of a recent trauma or bleeding. Four hundred and five patients with the same age and sex distribution and with proven malaria by microscopy acted as a positive control group.

\section{Group 2}

Children who came for follow-up on day three after initiation of treatment for acute, uncomplicated falciparum malaria at the health clinic attached to the hospital and who had cleared their parasitaemia microscopically. Patients with febrile illness other than malaria, with severe malaria, concomitant infections or known chronic disease were excluded. The children had received amodiaquine, artesunate or a combination of the two as part of an ongoing drug trial.

Children were enrolled after informed consent from parents or guardians. The ethics and protocol review committee at the University of Ghana Medical School had approved the study.

Blood was collected in EDTA-coated tubes and examined using an automated haematology analyser (Sysmex, KX21, Germany). Giemsa-stained blood films were prepared on day 0 (group 1) and on day 0 (i.e. prior to inclusion), 3 and 7 (group 2). Blood films were considered to be nega- 
Table I: Patient characteristics

\begin{tabular}{|c|c|c|c|c|c|}
\hline & \multicolumn{3}{|l|}{ Group I } & \multicolumn{2}{|l|}{ Group 2} \\
\hline & Persistent malaria & Recent malaria & No malaria & Persistent malaria & Recent malaria \\
\hline Number of patients & 16 & 15 & 17 & 8 & 39 \\
\hline Age' (years) & $2(1-12)$ & $4(0.5-10)$ & $2(0.5-12)$ & $5.8(1.5-10)$ & $5.8(1-12)$ \\
\hline Temperature on admission ${ }^{\prime}\left({ }^{\circ} \mathrm{C}\right)$ & $37.0(36.0-38.5)$ & $38.0(36.7-38.6)$ & $37.5(36.6-39.5)$ & $37.2(36.8-38.8)$ & $38.2(36.0-40.0)$ \\
\hline Sex (boys:girls) & $12: 4$ & $7: 8$ & $10: 7$ & $5: 3$ & $23: 15$ \\
\hline Haemoglobin' (g/dl) & $3.4(2.1-10.2)$ & $4.4(1.6-11.6)$ & $9.8(1.5-11.8)$ & $6.6(4.7-10.5)$ & $9.2(5.2-12.0)$ \\
\hline TNF- $\alpha(\mathrm{pg} / \mathrm{ml})^{2}$ & $16.2(6.9-38.0)$ & $13.5(6.5-27.5)$ & $5.4(1.2-23.4)$ & $6.2(0.6-63.1)$ & $8.7(5.5-13.5)$ \\
\hline $\mathrm{IL}-\mathrm{I} 0(\mathrm{pg} / \mathrm{ml})^{2}$ & $56.2(15.8-208.2)$ & $29.5(7.8-112.2)$ & $3.0(0.9-9.8)$ & $8.9(3.6-21.9)$ & $8.3(5.8-11.7)$ \\
\hline IL-I0/TNF- $\alpha^{2}$ & $1.9(1.0-3.6)$ & $1.4(0.4-5.6)$ & $1.0(0.5-2.3)$ & $1.7(0.1-46.8)$ & $1.0(0.5-2.0)$ \\
\hline
\end{tabular}

I: median (range)

2: mean $(95 \% \mathrm{Cl})$

tive if 200 leucocytes had been counted without finding parasites, corresponding to a detection level of approximately 50 parasites $/ \mu \mathrm{L}$. Antigen detection was performed on whole blood from day 0 (group 1) and day 3 (group 2). The rapid diagnostic tests, Now ${ }^{\oplus}$ ICT Malaria P.f/P.v (Binax, US) and Optimal ${ }^{\circledast}$ (DiaMed AG, Schweiz), were used according to the manufacturer's instruction.

The EDTA-plasma was subsequently collected by centrifugation and stored at $-20^{\circ} \mathrm{C}$ until analysis. Plasma concentrations of EPO, sTfR, TNF- $\alpha$ and IL-10 were measured using commercial ELISA kits according to the manufacturer's instructions (EPO, sTfR and IL-10, R\&D Systems, MN, USA and TNF- $\alpha$, BioSource International, CA, USA).

\section{Statistics}

All data, except haemoglobin, were logarithmically transformed to achieve normal distribution. Differences between groups were analysed using two-tailed student's t-test, except differences in haemoglobin levels that were analysed by Mann Whitney two sample rank sum test. Associations between parameters were analysed by multiple regression analyses. P-values $<0.05$ were considered statistically significant. All calculations were performed using Stata SE 8.0 (Stata Corporation, TX, USA)

\section{Results}

Forty eight patients were enrolled into group 1: 24 with severe anaemia and 24 with $\mathrm{Hb} \geq 8 \mathrm{~g} / \mathrm{dl}$. Two ( $8.3 \%)$ of the patients with severe anaemia and $15(62.5 \%)$ of those with $\mathrm{Hb} \geq 8 \mathrm{~g} / \mathrm{dl}$ had no detectable malaria antigens and were, thus, unlikely to suffer from malaria ('No malaria', Table 1). Of the remaining 31 patients, all had a positive HRP-2 test. Sixteen also had a positive pLDH test, suggestive of persistent malaria, whereas 15 had a positive HRP2 test only, suggestive of recent malaria. Among the patients with a positive antigen test, 25 reported to have taken some antimalarial medication prior to admission, four had not received treatment and information was missing for two patients. Forty seven patients were enroled into group 2 . Their median parasite density on day 0 was 25,633 parasites/ $\mu \mathrm{L}$ (25th -75 th percentiles: 5096 - 70,755). On the day of inclusion (day 3 ) all had undetectable parasitaemia by microscopy but had a positive HRP-2 test. Only eight had signs of persistent parasitaemia as indicated by the pLDH test. In both groups, patients with persistent malaria tended to have lower $\mathrm{Hb}$ than those with recent malaria; although in group 1, the difference did not reach statistical significance (group1: $\mathrm{P}$ $=0.19$ and group $2: \mathrm{P}=0.04$, Table 1 ). In order to simplify the result presentation, the two groups are combined, based on the assumption that subpatent $P$. falciparum infection played a similar role in both groups. However, since the groups had different age distribution and the clinical similarity between the groups could not be established, the data were also analysed separately for the groups. As indicated in the text, this did not affect the conclusions of the study.

\section{Erythropoiesis}

The bone marrow response to low $\mathrm{Hb}$ was compared between patients with positive $\mathrm{pLDH}$, (persistent malaria, $\mathrm{n}=24$ ) and those with negative pLDH, (recent malaria or no malaria, $n=71$ ) in order to detect an effect of persistent $\mathrm{P}$. falciparum infection on erythropoiesis. Both RDW and sTfR increased in response to low $\mathrm{Hb}$ as indicated by a negative correlation between RDW and $\mathrm{Hb}$ and between sTfR and Hb. However, the levels of RDW and sTfR were lower in patients with persistent infection (filled symbols) than in those with recent malaria or without signs of malaria (open symbols, Figure $1 \mathrm{~A}$ and $1 \mathrm{~B}$ ). In a multivariate regression analysis with haemoglobin and test results for PLDH and HRP2 as explanatory variables, a positive test for $\mathrm{PLDH}$, but not a positive test for HRP2 alone, was significantly associated with reduced levels of RDW and sTfR (Table 2). For this analysis, all patients in group 1 

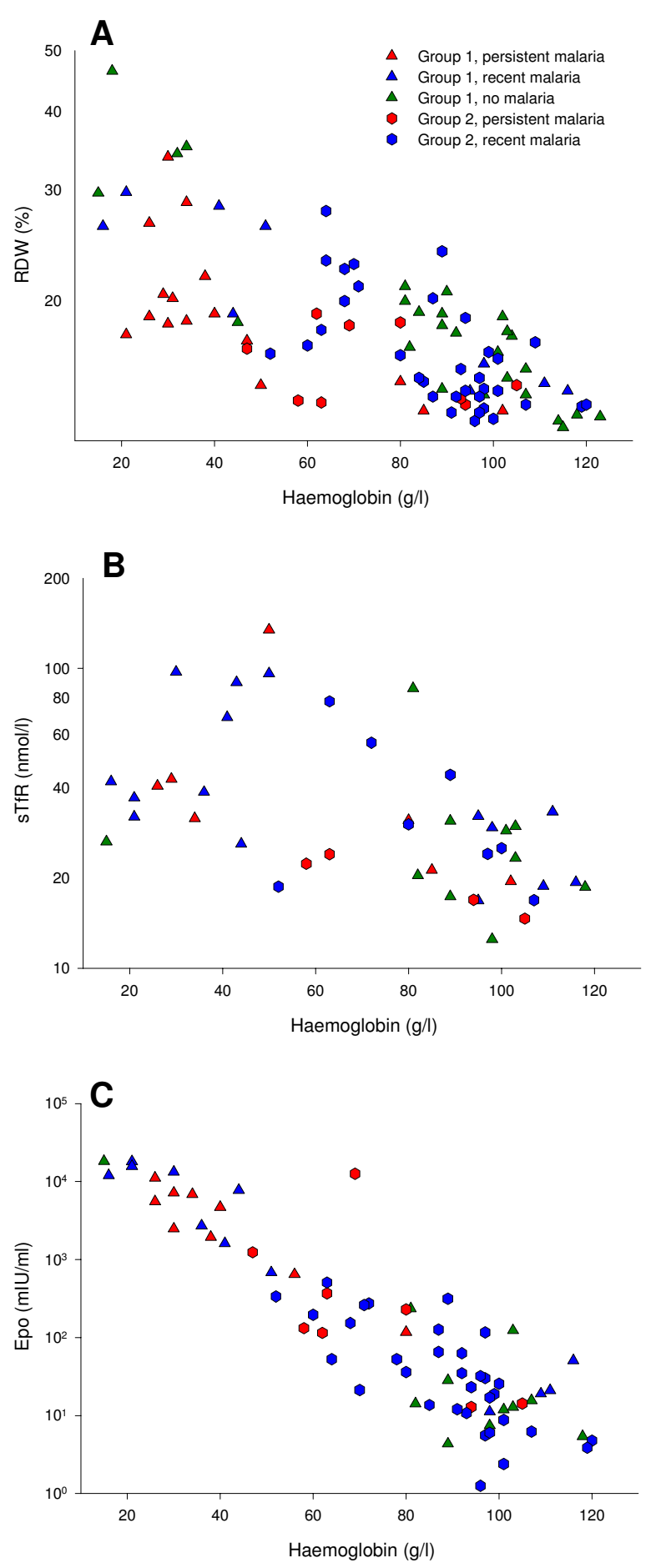

Figure I

Effect of $P$. falciparum on erythropoietic response to anaemia. Associations between haemoglobin and $(A)$ red cell distribution width (RDW), (B) soluble transferrin receptor (sTfR), and C. erythropoietin (EPO) in children with recent malaria ( $\mathrm{PLDH}$ negative, HRP2 positive), persistent, submicroscopic $P$. falciparum infection (pLDH and HRP2 positive) or without signs of malaria ( $\mathrm{PLDH}$ and HRP2 negative). and group 2 were combined in order to span the range of Hb-levels. However, when the multiple regression analysis was repeated for the two groups separately, the results were similar, although the association between pLDH and sTfR did not reach statistical significance (log RDW: group 1: $\mathrm{P}<0.001$ and group 2 : $\mathrm{P}<0.05$; $\log$ sTfR group $1: \mathrm{P}=$ 0.07 and group 2: $\mathrm{P}=0.08$ ). Persistent, microscopy negative malaria reduced the bone marrow response to the same extent as patent malaria. Thus, the slope of the regression line between RDW as the dependent and $\mathrm{Hb}$ as the independent variable was reduced to the same extent in microscopy negative patients with persistent malaria as in the 405 patients with a positive microscopy compared to patients without malaria (Figure 2, red slope, purple slope, and green slope, respectively, $\mathrm{P}<0.001$ for the comparison between no malaria and both other groups).

Plasma levels of EPO showed a strong inverse correlation with $\mathrm{Hb}$ (Figure 1C, $\mathrm{R}=-0.36,95 \% \mathrm{CI}$ : $-0.40--0.32, \mathrm{P}<$ 0.001 ), and neither PLDH nor HRP2 were correlated with EPO, indicating that $P$. falciparum infection did not affect the secretion of EPO (Table 2).

Forty patients in group 2 were followed up on day 7. In these, bone marrow suppression had receded and there was an inverse linear correlation between log RDW and $\mathrm{Hb}(\mathrm{R}=-0.05,95 \% \mathrm{CI}$ : $-0.06--0.04, \mathrm{P}<0.001$, Figure 3$)$. There was no difference between children who had a positive and those who had a negative test for pLDH on day three $(P=0.53)$, but two children remained severely anaemic.

\section{Cytokines}

The plasma levels of TNF- $\alpha$ and IL-10 were comparable to those in normal Ghanaian children without symptoms of malaria or detectable parasitaemia [2]. There was an inverse linear correlation between $\log$ IL10 and $\mathrm{Hb}(\mathrm{R}=-$ $0.08,95 \% \mathrm{CI}:-0.14--0.03, \mathrm{P}=0.005)$. There was no correlation between $\log \mathrm{TNF}-\alpha$ and $\mathrm{Hb}(\mathrm{P}=0.89)$. The regression line between RDW and $\mathrm{Hb}$ was not influenced by TNF $\alpha$, IL-10 or the IL-10/TNF- $\alpha$ ratio, irrespective of antigen test results (multiple regression analysis, IL-10, $\mathrm{P}=$ 0.40 , TNF- $\alpha, P=0.53$, IL-10/TNF- $\alpha, P=0.40)$. Analyses with sTfR as a dependent variable gave similar results (IL$10, \mathrm{P}=0.78$, TNF- $\alpha, \mathrm{P}=0.35$, IL-10/TNF- $\alpha, \mathrm{P}=0.63)$. On day 0 (i.e. prior to recruitment), patients in group 2 had elevated plasma IL-10 (mean (95\% CI) 450.4 (291.5$609.3) \mathrm{pg} / \mathrm{ml}$ ) and TNF- $\alpha$ (36.3 (25.7-51.3) pg/ml), but the levels were not correlated with $\mathrm{Hb}$ (IL-10, $\mathrm{P}=0.31$, TNF- $\alpha, P=0.30$, IL-10/TNF- $\alpha$ ratio, $\mathrm{P}=0.21$ ).

\section{Discussion}

Children living in areas with endemic malaria are usually assumed to have malaria if they are hospitalized with severe anaemia that is preceded by an acute febrile illness. 
Table 2: Association between markers of erythropoiesis and Plasmodium antigens in multiple regression analyses with haemoglobin and test results for parasite derived lactate dehydrogenase (pLDH) and histidine rich protein $2(H R P 2)$ as explanatory variables.

\begin{tabular}{lllllll}
\hline & PLDH & & HRP2 & & Haemoglobin \\
& $\beta(95 \% \mathrm{Cl})$ & P-value & $\beta(95 \% \mathrm{Cl})$ & P-value & $\beta(95 \% \mathrm{Cl})$ & $\mathrm{P}$-value \\
\hline $\operatorname{Log~RDW}^{\prime}(\%)$ & $-0.08(-0.1 \mathrm{l}-(-0.04))$ & $<0.001$ & $-0.04(-0.12-0.04)$ & 0.56 & $0.03(0.02-0.04)$ & $<0.001$ \\
$\log \mathrm{sTRR}^{2}(\mathrm{nmol} / \mathrm{l})$ & $-0.18(-0.32-(-0.03))$ & 0.02 & $0.08(-0.09-0.24)$ & 0.36 & $0.04(0.02-0.06)$ & $<0.001$ \\
$\log \mathrm{EPO}^{3}(\mathrm{mlU} / \mathrm{ml})$ & $0.13(-0.16-0.43)$ & 0.39 & $0.14(-0.18-0.47)$ & 0.38 & $0.34(0.30-0.39)$ & $<0.001$ \\
\hline
\end{tabular}

I: Red cell distribution width

2: Soluble transferrin receptor

3: Erythropoietin

Such patients often have undetectable malaria parasites by microscopy of Giemsa-stained blood films, but their leukocytes commonly contain detectable malaria pigment [15]. It has previously been shown that the diagnosis may be aided by the use of rapid antigen detection tests, which can distinguish patients with malarial anaemia from those with anaemia from other causes [7], and this was supported in the present study. Thus, more than $90 \%$ of the patients with severe anaemia had detectable parasite antigens compared to only one third of those with normal or near normal $\mathrm{Hb}$. Although microscopy is usually considered the gold standard for the diagnosis of malaria, these results suggest that the antigen detection methods, in particular those based on the detection of pLDH, may be superior to microscopy in the diagnosis of malarial anaemia.

In the present study, patients with detectable pLDH, a sign of persistent parasitaemia, were distinguished from those in whom only HRP2 could be detected as a sign of a cleared, recent infection. Only patients with persistent parasitaemia had signs of bone marrow suppression. This corresponds with previous investigations in which release of immature erythrocytes from the bone marrow coincided with the time of parasite clearance $[1,6]$ and with findings in experimental malaria [16]. In one such study, subpatent $P$. falciparum infection in vaccinated Aotus monkeys led to severe bone marrow suppression that was rapidly reversed in response to mefloquine induced parasite clearance [17].

The association between $P$. falciparum infection and suppression of erythropoiesis has been debated. Menendez et al. found that levels of sTfR were increased in infants with malaria [18]. Similarly, Verhoef found increased levels of sTfR in children with malaria and concluded that there was no suppression of erythropoiesis [19]. However, in these studies it was not indicated if levels of sTfR were increased adequately compared to the degree of anaemia. Furthermore, increased levels of sTfR found in malaria patients might be caused by shedding of receptors from proliferating B-lymphocytes [16]. In the present study, however, there was no correlation between sTfR and lymphocyte count (data not shown). Due to the logistics of the study it was not possible to make reticulocyte counts but the finding that persistent, subpatent parasitaemia was associated with reduced levels of both RDW and sTfR strongly points toward parasite-induced suppression of erythropoiesis. This may explain the fact that healthy school children with so-called asymptomatic $P$. falciparum infection have reduced $\mathrm{Hb}$ and signs of bone marrow suppression [2]. Asymptomatic P. falciparum infections are usually accepted as a necessary evil in order to maintain immunity in individuals, who are at great and constant risk of malarial infections [20], and this approach is probably the only realistic option in the near future. However, data from the present study imply that the ultimate goal of malaria control ought to be complete parasite eradication due to the detrimental effects of persistent parasitaemia. This is consistent with a previous clinical trial that linked incomplete haematological recovery with lack of parasitological cure [21]. The Hb levels in infants living with high risk of malaria can be improved by impregnated bednets [22], malaria chemoprophylaxis [23] and presumptive intermittent treatment [24]. It is likely that this effect is mediated partly by a reduction in the risk of bone marrow suppression. From a clinical point of view this study suggests that in malarial endemic areas, antimalarial treatment should not be withheld from severely anaemic patients presenting with signs compatible with ongoing or recent malaria who have not been treated for malaria, even when parasites are undetectable by microscopy. Controlled clinical trials should be performed to determine whether patients who have already received a full course of antimalarial treatment would benefit from a repeat course, and in particular, if it is important to restrict this treatment to children with a positive pLDH test. Paediatric patients that return with repeated episodes of anaemia are common (ref. 7) and the management of these patients puts strain on the health system. Thus, the cost of 


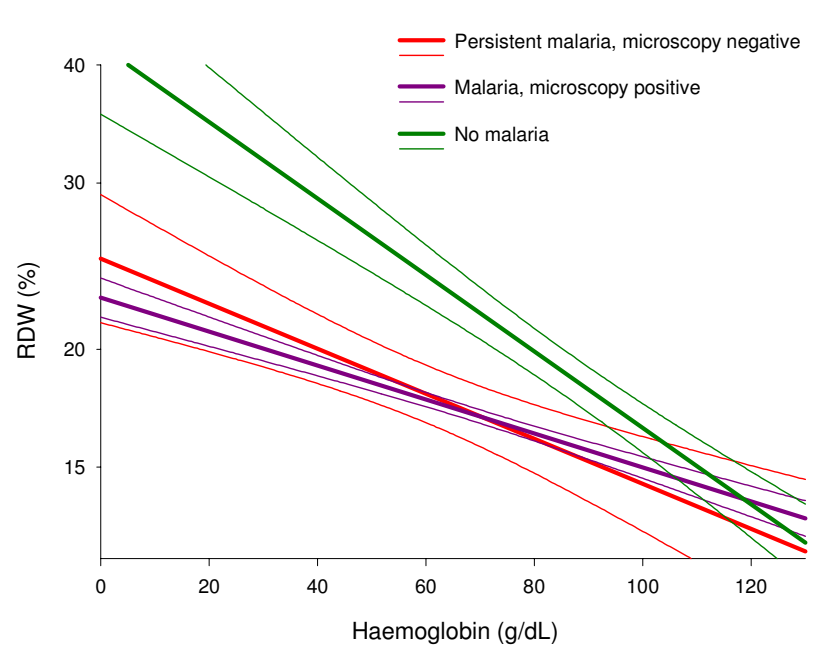

Figure 2

Comparison of the effect of patent versus subpatent $P$. falciparum infection on erythropoietic response to anaemia. Association between haemoglobin and red cell distribution width (RDW) in microscopy negative children with persistent malaria, children with microscopically detectable parasites and children without malaria. Regression lines and $95 \%$ confidence intervals.

improved diagnosis and management of these cases have the potential to benefit both the patients and the health system.

Several studies have shown that the suppressed bone marrow response to anaemia, which is a general feature of malaria, is not caused by insufficient secretion of EPO $[1,25,26]$, but this is disputed by other investigations [2729]. In agreement with the former view, similar levels of EPO in response to low $\mathrm{Hb}$ were found in patients with and without malaria. It has been suggested that the bone marrow suppression is a direct effect of TNF- $\alpha$, which is elevated in malaria [30]. On the other hand, other investigations did not find that inflammatory cytokines to played a role in malarial dyserythropoiesis [31]. In addition, severe malarial anaemia is associated with relatively low TNF- $\alpha$ levels [32] and signs of systemic inflammation [33,34] (Awandare et al. unpublished data) compared with cerebral malaria and uncomplicated malaria. It is thus possible that the effect of cytokine perturbations in malarial anaemia is a lack of parasite control that leads to persistence of the infection and thus indirectly causes bone marrow suppression [32]. It has recently been proposed that phagocytosed haemozoin may play a role in the dyserythropoiesis of malaria through induction of 4hydroxynonenal [35].

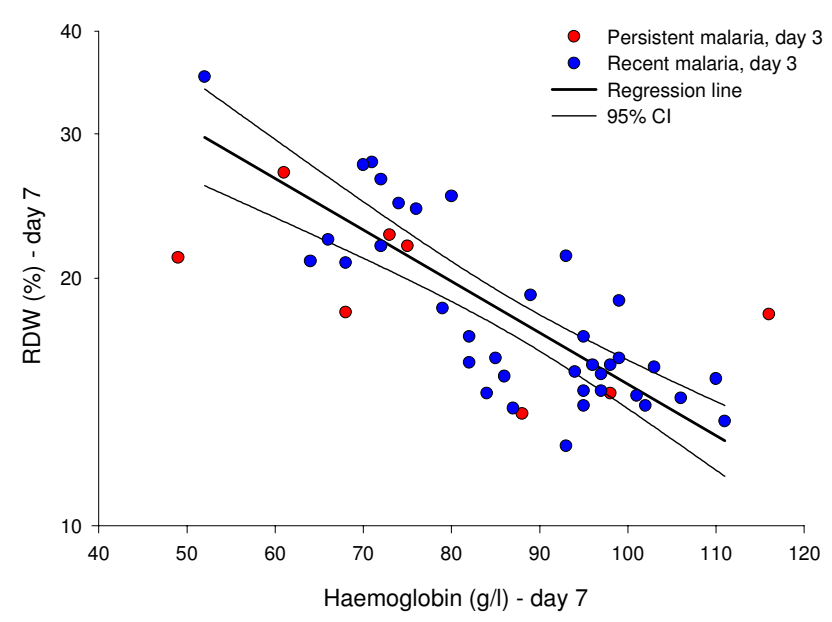

Figure 3

Erythropoietic response to anaemia after clearance of $\boldsymbol{P}$. falciparum. Association between haemoglobin and red cell distribution width (RDW) on day 7. Regression line and $95 \%$ confidence interval.

\section{Conclusion}

This study has shown that the majority of severe anaemia cases in children living in areas with malaria transmission is due to malaria. This is also the case when no malaria parasites can be detected by microscopy, in which case antigen detection may lead to the diagnosis. These patients have suppressed erythropoiesis, which persists until the parasites have been cleared completely.

\section{Authors' contributions}

Marie Helleberg and Jorgen A. L. Kurtzhals designed the study in collaboration with all co-authors. Marie Helleberg, Bamenla Q. Goka, George Obeng-Adjei and Onike Rodriques performed the clinical work; Marie Helleberg and Bartholomew D. Akanmori did the laboratory analysis. Marie Helleberg did the data analysis and drafted the manuscript. All authors contributed significantly to the final version of the manuscript. The authors do not have any commercial or other association that might pose a conflict of interest.

\section{Financial support}

The study was supported by grants from the Danish Medical Research Council (SSVF grant no. 22-01-0343 and 2203-0063) and the Danish International Development Assistance.

\section{Acknowledgements}

We are grateful for the collaboration of the patients and the parents, the assistance of the staff at the Department of Child Health, Korle Bu Teaching Hospital and to the staff in the research laboratory. 


\section{References}

I. Kurtzhals JA, Rodrigues O, Addae M, Commey JO, Nkrumah FK, Hviid L: Reversible suppression of bone marrow response to erythropoietin in Plasmodium falciparum malaria. $\mathrm{Br} J$ Haematol 1997, 97:169-174.

2. Kurtzhals JA, Addae MM, Akanmori BD, Dunyo S, Koram KA, Appawu MA, Nkrumah FK, Hviid L: Anaemia caused by asymptomatic Plasmodium falciparum infection in semi- immune African schoolchildren. Trans R Soc Trop Med Hyg 1999, 93:623-627.

3. Phillips RE, Pasvol G: Anaemia of Plasmodium falciparum malaria. Baillieres Clin Haematol 1992, 5:315-330.

4. Phillips RE, Looareesuwan S, Warrell DA, Lee SH, Karbwang J, Warrell MJ, White NJ, Swasdichai C, Weatherall DJ: The importance of anaemia in cerebral and uncomplicated falciparum malaria: role of complications, dyserythropoiesis and iron sequestration. QJ Med 1986, 58:305-323.

5. Camacho LH, Gordeuk VR, Wilairatana P, Pootrakul P, Brittenham GM, Looareesuwan S: The course of anaemia after the treatment of acute, falciparum malaria. Ann Trop Med Parasitol 1998, 92:525-537.

6. Abdalla S, Weatherall DJ, Wickramasinghe SN, Hughes M: The anaemia of P. falciparum malaria. Br J Haematol I980, 46: I7I-I83.

7. Kurtzhals JA, Helleberg M, Goka BQ, Akanmori BD: Severe malaria in west African children. Lancet 2003, 36 I:1393.

8. Kurtzhals JA, Adabayeri V, Goka BQ, Akanmori BD, Oliver-Commey JO, Nkrumah FK, Behr C, Hviid L: Low plasma concentrations of interleukin 10 in severe malarial anaemia compared with cerebral and uncomplicated malaria. Lancet 1998, 35 I: I768-I772.

9. Biemba G, Gordeuk VR, Thuma PE, Mabeza GF, Weiss G: Prolonged macrophage activation and persistent anaemia in children with complicated malaria. Trop Med Int Health 1998, 3:60-65.

10. Wickramasinghe SN, Abdalla SH: Blood and bone marrow changes in malaria. Baillieres Best Pract Res Clin Haematol 2000, I 3:277-299.

II. Tjitra E, Suprianto S, McBroom J, Currie BJ, Anstey NM: Persistent ICT malaria P.f/P.v panmalarial and HRP2 antigen reactivity after treatment of Plasmodium falciparum malaria is associated with gametocytemia and results in false-positive diagnoses of Plasmodium vivax in convalescence. I Clin Microbiol 200I, 39:1025-103I.

12. Piper R, Lebras J, Wentworth L, Hunt-Cooke A, Houze S, Chiodini P, Makler M: Immunocapture diagnostic assays for malaria using Plasmodium lactate dehydrogenase (pLDH). Am J Trop Med Hyg 1999, 60:109-118

13. Roberts GT, El Badawi SB: Red blood cell distribution width index in some hematologic diseases. Am J Clin Pathol 1985, 83:222-226.

14. Beguin Y, Clemons GK, Pootrakul P, Fillet G: Quantitative assessment of erythropoiesis and functional classification of anemia based on measurements of serum transferrin receptor and erythropoietin. Blood 1993, 81:1067-1076.

15. FK N: Severe anaemia associated with malaria in children. Ghana Med J 1973, I 2: 17-2I.

16. Chang KH, Tam M, Stevenson MM: Inappropriately low reticulocytosis in severe malarial anemia correlates with suppression in the development of late erythroid precursors. Blood 2004, I 03:3727-3735.

17. Egan AF, Fabucci ME, Saul A, Kaslow DC, Miller LH: Aotus New World monkeys: model for studying malaria-induced anemia. Blood 2002, 99:3863-3866.

18. Menendez C, Quinto LL, Kahigwa E, Alvarez L, Fernandez R, Gimenez N, Schellenberg D, Aponte JJ, Tanner M, Alonso PL: Effect of malaria on soluble transferrin receptor levels in Tanzanian infants. Am J Trop Med Hyg 200I, 65: I 38-142.

19. Verhoef H, West CE, Kraaijenhagen R, Nzyuko SM, King R, Mbandi $M M$, van Laatum S, Hogervorst R, Schep C, Kok FJ: Malarial anemia leads to adequately increased erythropoiesis in asymptomatic Kenyan children. Blood 2002, I 00:3489-3494.

20. Kitua AY, Smith TA, Alonso PL, Urassa H, Masanja H, Kimario J, Tanner $M$ : The role of low level Plasmodium falciparum parasitaemia in anaemia among infants living in an area of intense and perennial transmission. Trop Med Int Health 1997, 2:325-333.

21. Bloland PB, Lackritz EM, Kazembe PN, Were JB, Steketee R, Campbell $\mathrm{CC}$ : Beyond chloroquine: implications of drug resistance for evaluating malaria therapy efficacy and treatment policy in Africa. J Infect Dis 1993, 167:932-937.

22. PL A, SW L, JRM AS, K K, P G, al. SFC: A malaria control trial using insecticide-treated bed nets and targeted chemoprophylaxis in a rural area of The Gambia, West Africa. 6. The impact of the interventions on mortality and morbidity from malaria. Trans R Soc Trop Med Hyg 1993, 87:S2/37-S2/44.

23. Menendez C, Kahigwa E, Hirt R, Vounatsou P, Aponte JJ, Font F, Acosta CJ, Schellenberg DM, Galindo CM, Kimario J, Urassa H, Brabin B, Smith TA, Kitua AY, Tanner M, Alonso PL: Randomised placebo-controlled trial of iron supplementation and malaria chemoprophylaxis for prevention of severe anaemia and malaria in Tanzanian infants. Lancet 1997, 350:844-850.

24. Massaga JJ, Kitua AY, Lemnge MM, Akida JA, Malle LN, Ronn AM, Theander TG, Bygbjerg IC: Effect of intermittent treatment with amodiaquine on anaemia and malarial fevers in infants in Tanzania: a randomised placebo-controlled trial. Lancet 2003 , 36 I: |853-1860.

25. Burchard GD, Radloff P, Philipps J, Nkeyi M, Knobloch J, Kremsner PG: Increased erythropoietin production in children with severe malarial anemia. Am J Trop Med Hyg 1995, 53:547-55I.

26. Rencricca NJ, Stout JP, Coleman RM: Erythropoietin production in virulent malaria. Infect Immun 1974, I 0:83 I-833.

27. Burgmann H, Looareesuwan S, Kapiotis S, Viravan C, Vanijanonta S, Hollenstein U, Wiesinger E, Presterl E, Winkler S, Graninger W: Serum levels of erythropoietin in acute Plasmodium falciparum malaria. Am J Trop Med Hyg 1996, 54:280-283.

28. El Hassan AM, Saeed AM, Fandrey J, Jelkmann W: Decreased erythropoietin response in Plasmodium falciparum malaria-associated anaemia. Eur J Haematol 1997, 59:299-304.

29. Vedovato M, De PV, Dapporto M, Salvatorelli G: Defective erythropoietin production in the anaemia of malaria. Nephrol Dial Transplant 1999, 14:1043-1044.

30. Clark IA, Chaudhri G: Tumour necrosis factor may contribute to the anaemia of malaria by causing dyserythropoiesis and erythrophagocytosis. BrJ Haematol 1988, 70:99-103.

31. Yap GS, Stevenson MM: Inhibition of in vitro erythropoiesis by soluble mediators in Plasmodium chabaudi AS malaria: lack of a major role for interleukin I, tumor necrosis factor alpha, and gamma interferon. Infect Immun 1994, 62:357-362.

32. Akanmori BD, Kurtzhals JA, Goka BQ, Adabayeri V, Ofori MF, Nkrumah FK, Behr C, Hviid L: Distinct patterns of cytokine regulation in discrete clinical forms of Plasmodium falciparum malaria. Eur Cytokine Netw 2000, I I: I I3- I I8.

33. JA K, CM R, E T, SK D, KA K, BD A, FK N, L H: Increased eosinophil activity in acute Plasmodium falciparum infection -association with cerebral malaria. Clin Exp Immunol 1998, I | 2:303-307.

34. Ostrowski SR, Ullum H, Goka BQ, Høyer-Hansen G, Obeng-Adjei G, Pedersen BK, Akanmori BD, Kurtzhals JAL: The plasma level of the soluble urokinase receptor is increased in malaria patients and associated with a poor clinical or fatal outcome. J Infect Dis 2005, 191:1331-1341.

35. G G, D U, E S, I R, W P, P A: Hemozoin- and 4-hydroxynonenalmediated inhibition of erythropoiesis. Possible role in malarial dyserythropoiesis and anemia. Haematologica 2004, 89:492-493.

Publish with Biomed Central and every scientist can read your work free of charge

"BioMed Central will be the most significant development for disseminating the results of biomedical research in our lifetime. "

Sir Paul Nurse, Cancer Research UK

Your research papers will be:

- available free of charge to the entire biomedical community

- peer reviewed and published immediately upon acceptance

- cited in PubMed and archived on PubMed Central

- yours - you keep the copyright
BiolMedcentral 